\title{
Evaluating health-related quality of life in type I diabetes: a systematic literature review of utilities for adults with type I diabetes
}

\author{
This article was published in the following Dove Press journal: \\ ClinicoEconomics and Outcomes Research \\ 7 October 2016 \\ Number of times this article has been viewed
}

\author{
Jayne Smith-Palmer ${ }^{1}$ \\ Jay $\mathrm{P} \mathrm{Bae}{ }^{2}$ \\ Kristina S Boye ${ }^{2}$ \\ Kirsi Norrbacka ${ }^{3}$ \\ Barnaby Hunt ${ }^{1}$ \\ William J Valentine' \\ 'Ossian Health Economics and \\ Communications $\mathrm{GmbH}$, Basel, \\ Switzerland; ${ }^{2}$ Eli Lilly and Company, \\ Indianapolis, IN, USA; ${ }^{3}$ Eli Lilly Finland, \\ Helsinki, Finland
}

Background and aims: Type 1 diabetes is a chronic condition associated with micro- and macrovascular complications that have a notable impact on health-related quality of life, the magnitude of which can be quantified via the use of utility values. The aim of this review was to conduct a systematic literature review to identify and compare published health state utility values for adults with type 1 diabetes both, with and without diabetes-related complications. Methods: Literature searches of the PubMed, EMBASE, and Cochrane Library databases were performed to identify English language studies on adults with type 1 diabetes, published from 2000 onward, reporting utility values for patients with or without diabetes-related complications or assessing the impact of changes in HbA1c or body mass index on quality of life. For inclusion, studies were required to report utilities elicited using validated methods.

Results: A total of 20 studies were included in the final review that included utility values elicited using the EuroQuol five dimensions questionnaire $(n=9), 15 D$ questionnaire $(n=2)$, Quality of Well-Being scale ( $n=4)$, time trade-off $(n=3)$, and standard gamble $(n=2)$ methods. For patients with no complications, reported utility values ranged from 0.90 to 0.98 . Complications including stroke (reported disutility range, -0.105 to -0.291 ), neuropathy (range, -0.055 to -0.358 ), and blindness (range, -0.132 to -0.208 ) were associated with the largest decrements in utility values. The magnitude of utility values and utility decrements was influenced by the assessment method used.

Conclusion: Complications lead to impaired health-related quality of life in patients with type 1 diabetes, the magnitude of which is influenced by the method used to determine utilities. There is currently a lack of utility data for certain complications of type 1 diabetes, meaning that many economic evaluations have relied on a combination of type 1 and type 2 diabetes utilities, despite differences between the conditions and populations, or type 1 diabetes-specific utilities derived from different instruments.

Keywords: type 1 diabetes; quality of life; health status; complications

\section{Introduction}

Type 1 diabetes is a chronic disease that is frequently associated with complications such as cardiovascular disease, peripheral neuropathy, diabetic foot complications, renal disease, and diabetic retinopathies. As well as having a significant clinical and economic impact, diabetes-related complications can also be detrimental to a patient's health-related quality of life (HRQoL). HRQoL is defined by the US Office of Disease
Correspondence: Jayne Smith-Palmer Ossian Health Economics and Communications $\mathrm{GmbH}$, Bäumleingasse 20, 405I Basel, Switzerland

$\mathrm{Tel}+4 \mid$ 6I 27| 62I4

Email smith-palmer@ossianconsulting. com 
Prevention as a "multi-dimensional concept that includes domains related to physical, mental, emotional, and social functioning." Patient-reported outcomes such as HRQoL represent an important component in terms of evaluating the impact of disease, as well as the effectiveness of treatments, on patients' day-to-day activities. However, in some therapy areas, differences in HRQoL have traditionally been considered difficult to directly quantify due to its subjective and multidimensional nature.

The assessment of HRQoL forms an integral part of health economic evaluations for new therapies, as economic models seek to capture the HRQoL impact of new interventions not only on the course of the disease itself but also on long-term complications and adverse events that may be associated with particular therapies. The use of utility values allows quality of life to be quantified on a scale of $0-1$, with a utility value of 0 corresponding to death and 1 corresponding to the best possible health or perfect health (although some instruments such as the EuroQuol five dimensions questionnaire [EQ-5D] and Health Utilities Index 3 allow for values $<0$, which indicate health states worse than death). The use of utility values allows the impact of a condition or treatment to be quantified and comparative analyses to be conducted. Different methods of calculating utilities exist: utility values for a health state can be solicited directly using standard gamble (SG), time trade-off(TTO), or a visual analog scale. Utilities can also be calculated via indirect methods such as using a HRQoL questionnaire that already has utility values previously evaluated by the developers using SG, TTO or VAS. Additionally, some patient-reported outcome measures have been used to estimate utilities by cross-walking the instruments to an HRQoL questionnaire that already has developed utility values. However, this method is rarely validated.

Published studies in patients with diabetes have employed several different tools for assessing HRQoL, including the EQ-5D, Short-form-36, Quality of Well-Being (QWB) scale, the Diabetes Quality of Life Clinical Trial Questionnaire, and the Audit of Diabetes-Dependent Quality of Life. Some of these instruments (eg, the EQ-5D and QWB) produce health state utility values using preference weights obtained from TTO, SG, or visual analog scale using regression methods. Measures such as the EQ-5D, Short-form-36, and QWB scale offer an advantage in terms of comparing different disease states. However, the limitation of generic instruments is that they may lack the discriminatory ability to detect subtle changes in disease-specific symptoms. Additionally, two versions of the EQ-5D exist, in the EQ-5D-3L there are three levels of severity for responses (no problems/some or moderate problems/extreme problems), in the EQ-5D-5L, there are five levels of severity for responses (no problems/slight problems/moderate problems/severe problems/extreme problems).

Many reimbursement authorities demonstrate no preference for the methods used to elicit utility values that inform health economic analyses in reimbursement submissions, simply stating that the choice of method should be appropriate and justified. Others have listed several methods that may be considered acceptable. ${ }^{2}$ A small number of reimbursement authorities, including the UK National Institute for Health and Care Excellence (NICE), advocate the use of the EQ-5D as the preferred method for the assessment of health state utility values. However, the NICE does acknowledge that there may be instances in which the EQ-5D instrument is inappropriate. ${ }^{3}$

Assessments of HRQoL in the general population typically yield utility values $<1$ (the best possible health or perfect health), and patients with chronic conditions frequently have lower mean values when compared with the general population. For example, reported utility values in chronic diseases include 0.88 (EQ-5D-3L) for hepatitis B patients with compensated cirrhosis, ${ }^{4} 0.73$ for patients with moderate chronic obstructive pulmonary disease, ${ }^{5}$ and $0.66-0.72$ for patients with rheumatoid arthritis. ${ }^{6}$ Similarly, examples of values obtained from general population samples include values of 0.868 and 0.845 reported for US and UK adult populations, respectively. ${ }^{7,8}$

A relatively large number of studies have examined the impact of diabetes-related complications on HRQoL in patients with type 2 diabetes. However, type 1 diabetes accounts for only $5 \%-10 \%$ of the total cases of diabetes worldwide and the impact of the condition and its complications is less well characterized. ${ }^{9}$ Indeed, several previously published cost-effectiveness analyses in patients with type 1 diabetes have partially or wholly utilized utility data gathered from populations with type 2 diabetes. ${ }^{10-12}$ However, the utility findings from studies on patients with type 2 diabetes may not translate directly to patients with type 1 diabetes because of differences in the etiology of disease and populations of type 1 and type 2 diabetes. For example, type 1 diabetes is typically diagnosed in childhood or adolescence, whereas type 2 diabetes is typically diagnosed much later in life. Furthermore, all type 1 diabetes patients are treated with insulin as opposed to type 2 diabetes patients who are typically treated initially with diet and exercise, oral antidiabetic agents, and subsequently initiate insulin therapy 4-12 years after diagnosis. ${ }^{13,14}$ Complication rates also differ between type 1 and type 2 diabetes. ${ }^{15,16}$ Studies on several chronic conditions, including diabetes, have shown that age and duration of disease influence HRQoL, ${ }^{17-19}$ and, as such, type 1 and type 2 diabetes patients of similar age may 
have notable differences in disease duration that may lead to HRQoL differences.

The aim of this review was to identify and compare published health state utility values for adult patients (aged $\geq 18$ years) with type 1 diabetes with and without diabetesrelated complications. The scope of this review also included the impact of glycemic control, obesity, and fear of hypoglycemia on HRQoL in this population.

\section{Methods}

A systematic literature review was performed to identify studies that elicited utility values for adult patients with type 1 diabetes with no complications or with disease-related complications including, but not limited to, hypoglycemia, renal disease, neuropathy, diabetic foot, amputation, retinopathy, blindness, myocardial infarction, angina, and stroke. This review was also designed to capture other outcomes associated with diabetes, such as the influence of glycemic control, fear of hypoglycemia, and changes in body mass index (BMI) on HRQoL.

For inclusion, studies were required to be conducted in adults (aged $\geq 18$ years) with type 1 diabetes, published in English since January 1,2000 , to report health state utility values elicited using validated methods, and published as full-text articles. Studies on mixed populations of type 1 and type 2 diabetes or pediatric type 1 diabetes and those published as abstracts, conference posters, and oral presentations were excluded.

Literature search strategies were designed using high-level Medical Subject Heading (MeSH) terms supplemented with free-text terms. Searches were performed on the PubMed, EMBASE, and Cochrane Library databases (full details of search strategies used are available from the authors upon request). Supplementary hand searches of the University of Sheffield School of Health and Related Research Health Utilities Database (ScHARRHUD) and the Tufts Cost-effectiveness Analysis Registry were also performed. Exclusion criteria were as follows: not performed in adults ( $\geq 18$ years) with type 1 diabetes, not presenting utility values for relevant health states, not published in English, and not reporting utility scores.

\section{Results}

After removal of duplicates, searches of the PubMed, EMBASE, and Cochrane Library databases yielded a total of 5,371 unique hits (Figure 1). Identified references were screened by two researchers using proprietary literature screening software (Sourcerer. Covalence Research Ltd, London, UK.

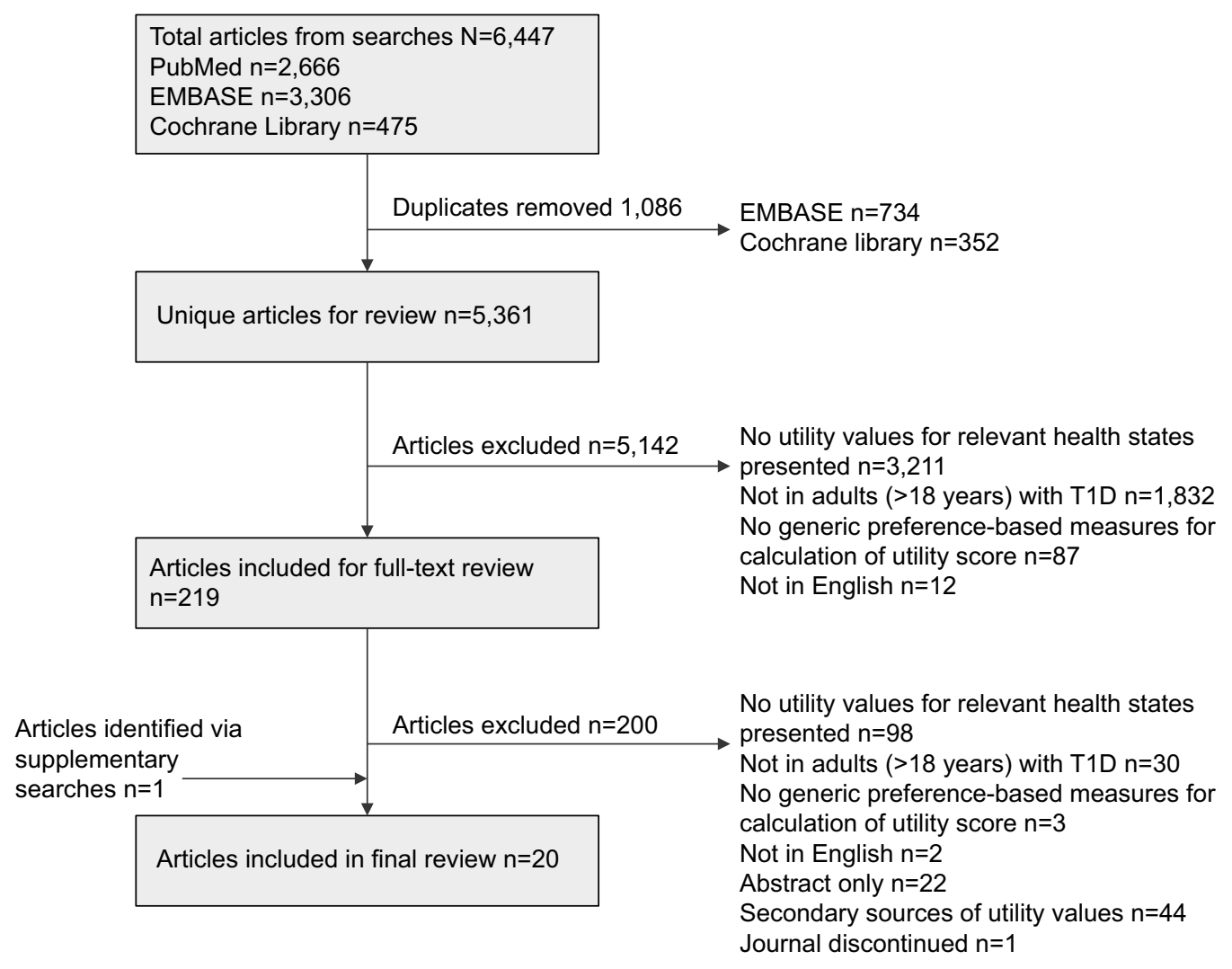

Figure I Schematic diagram of literature review process. 
Available at https://sourcerer.pro/). A total of 5,142 articles were excluded during first round of screening of titles and abstracts (disagreements between the two researchers $[n=118]$ were resolved by consensus following discussion), and a further 200 articles were excluded during a second round of screening, leaving a total of 19 articles for inclusion in the review. One additional article for inclusion was identified via supplementary hand searches. No additional articles were identified from searches of the Tufts Cost-effectiveness Analysis Registry or the ScHARRHUD. Of the included studies, a total of nine used the EQ-5D-3L or $-5 \mathrm{~L}^{20-28}$ and eleven used other methods including the generic $15 \mathrm{D}^{29,30}$ and $\mathrm{QWB}^{31-34}$ questionnaires and direct methods including $\mathrm{TTO}^{35-37}$ and SG. ${ }^{38,39}$

\section{Overview of utilities by complication}

Analysis of utilities according to complication showed that blindness, neuropathy, and stroke were the complications consistently associated with the largest utility decrements
(Figure 2). Type 1 diabetes is associated with increased risk for ophthalmic complications, and utility values were reported for states of retinopathy, impaired vision, and blindness. The presence of retinopathy and other states where patients maintained vision had a small impact on HRQoL. Disutility values (presented by increasing severity) ranged from -0.007 to $-0.048^{21,30}$ for retinopathy, to -0.063 for impaired vision, ${ }^{24}$ and to -0.024 for blindness in one eye.$^{33}$ Blindness in both eyes was consistently associated with a notable utility decrement with two studies reporting values of $0.48^{39}$ and $0.52^{35}$ and utility decrements (disutilities) ranging from $-0.132^{32}$ to -0.208 . $^{33}$

Stroke was also consistently associated with substantial impact on HRQoL with Lee et $\mathrm{a}^{35}$ reporting a utility value of 0.34 and disutility values ranging from $-0.105^{33}$ to $-0.291 .^{24}$ Notably, only one study included in the review differentiated between stroke and transient ischemic attack.

The impact of renal disease on HRQoL was found to be highly variable. For patients with end-stage renal

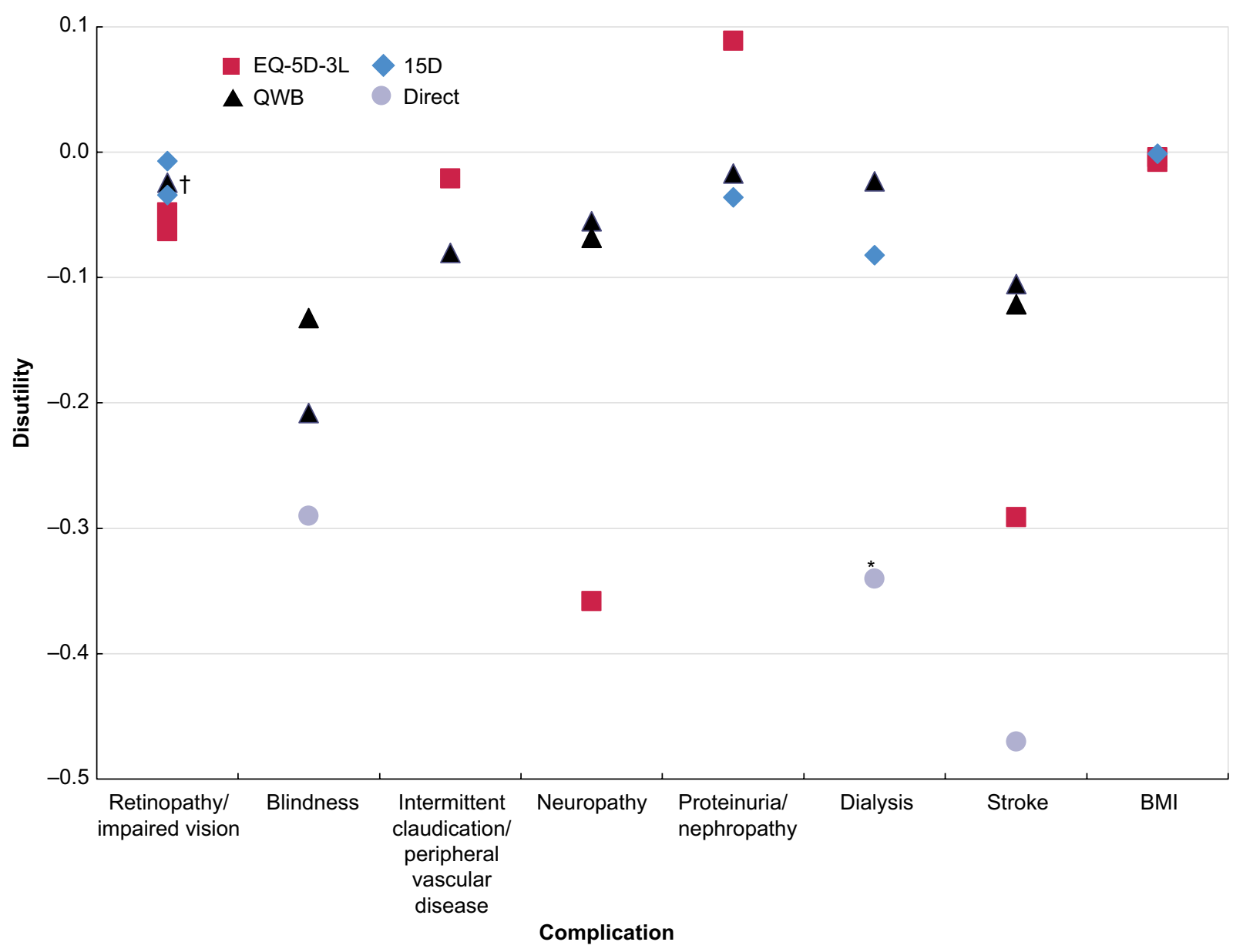

Figure 2 Disutility values for diabetes-related complications in type I diabetes.

Notes: Only complications where more than one disutility value was reported are shown. BMI refers to the disutility per I unit increase in BMI. *End-stage renal disease. 'Blindness in one eye.

Abbreviations: BMI, body mass index; EQ-5D, EuroQol five dimensions questionnaire; QWB, Quality of Well-Being. 
disease (ESRD), reported utility values ranged from $0.47^{35}$ to $0.70^{38}$ and disutilities from $-0.023^{33}$ to $-0.082 .^{30}$ Utility values for patients with a functioning renal transplant were also inconsistent with utility values ranging from $0.54^{31}$ to $0.80,{ }^{38}$ and Ahola et $\mathrm{al}^{30}$ reported a disutility of just -0.053 . Patients with simultaneous kidney and pancreas transplant consistently had better HRQoL than those with kidney-alone transplants and were among some of the highest values identified in the review, with utility values for simultaneous kidney-pancreas transplant ranging from $0.62^{31}$ to $0.95 .^{39}$

Data on cardiovascular complications were limited, with two studies using the umbrella term "macrovascular complications" to report disutilities of $-0.146^{20}$ and $-0.135 .{ }^{21}$ Only one study reported a utility value for angina, which was $0.74 .{ }^{35}$ No type 1 -specific utilities were reported for myocardial infarction, but ischemic heart disease, which includes both angina and myocardial infarction, was associated with a disutility of $-0.181 .{ }^{24}$ Only one study quantified the impact of congestive heart failure on HRQoL, which was associated with a more modest disutility of $-0.058 .{ }^{33}$

As expected, studies that examined the impact of hypoglycemic events consistently reported a larger disutility for severe events than for nonsevere events. For severe daytime events, disutilities of $-0.0277^{36}$ and $-0.047^{37}$ were reported, while another study reported a utility value of 0.522 for severe events (compared with 0.644 for no events; a difference of $-0.122) .{ }^{39}$ Similarly, for nonsevere daytime events, disutilities of $-0.0030^{36}$ and $-0.004^{37}$ were reported, and Currie et $\mathrm{al}^{27}$ reported a utility value of 0.758 for mild hypoglycemia (vs 0.644 for no events).

\section{EQ-5D instrument}

The EQ-5D is considered the preferred method for eliciting health state utility values by some reimbursement authorities, including NICE, and nine studies were identified that used this instrument. ${ }^{40}$ For overall populations of type 1 diabetes patients, including those with and without chronic complications, reported EQ-5D-3L utility values ranged from $0.658^{27}$ to $0.909^{22}$ (Table 1). Only two studies reported values for type 1 diabetes without complications, which were $0.90^{24}$ and $0.982 .{ }^{26}$ This difference may be partly attributable to differences in the mean age and duration of disease between the populations in the two studies, although there may be other unknown factors contributing to the difference observed. One EQ-5D-3L study by Solli et al, which described an analysis of 165 type 1 diabetes patients in Norway, examined the HRQoL impact of any complication as well as specific complications. Here, the presence of one complication was associated with a mean (95\% confidence interval [CI]) utility of $0.76(0.66-0.86)$ (vs
0.90 [0.88-0.93] for no complications), while the presence of two or more complications reduced the utility value to 0.55 (0.37-0.73). In terms of individual complications, Solli et $\mathrm{al}^{24}$ reported that the presence of neuropathy had the largest impact on HRQoL, being associated with a utility decrement (or disutility) of -0.358 ( -0.535 to -0.180$)$, followed by stroke (disutility of $-0.291[-0.475$ to -0.108$]$ ). Additionally, the presence of ischemic heart disease was associated with a disutility of $-0.181(-0.331$ to -0.031$) .{ }^{24}$ In two articles by Hart et al, the impact of macrovascular complications (angina, myocardial infarction, intermittent claudication, transient ischemic attack, and cerebrovascular accident) was assessed. In these studies, both in type 1 diabetes patients in the Netherlands, the presence of macrovascular complications was associated with a disutility of $-0.135^{21}$ and $-0.146 .{ }^{20}$

Although not considered to be a diabetes-related complication, two studies examined the impact of glycemic control (HbA1c) on HRQoL using the EQ-5D-3L or -5L (Table 1). ${ }^{22,28}$ In a US-based study of 176 patients, those with HbA1c of $6 \%$ were projected to have a utility value of 0.955 , decreasing to 0.900 with a $\mathrm{HbA} 1 \mathrm{c}$ of $8 \%$ and 0.845 for a $\mathrm{HbA} 1 \mathrm{c}$ of $10 \%$. Similarly, when treated as a continuous variable, a $1 \%$ increase in $\mathrm{HbA} 1 \mathrm{c}$ was associated with a disutility of $-0.027 .{ }^{22}$ In a UK-based study, Ozcan et $\mathrm{al}^{28}$ observed that for both patients with hypoglycemia awareness and impaired hypoglycemia awareness, EQ-5D-5L scores decreased with poor glycemic control. For those hypoglycemia-aware patients with $\mathrm{HbA} 1 \mathrm{c}<7.0 \%$, the mean (standard deviation [SD]) utility value was 0.88 (0.04), which decreased to 0.75 (0.03) for those with HbA1c $>8.5 \%$. The corresponding figures for patients with impaired hypoglycemia awareness were $0.83(0.05)$ and $0.69(0.05)$, respectively. ${ }^{28}$ Again, although not strictly considered a disease-related complication, two studies examined the impact of BMI on HRQoL using the EQ-5D-3L reporting utility decrements of -0.004 and -0.0076 per unit increase in BMI. ${ }^{24,25}$

The literature review process identified a total of two studies that investigated the HRQoL impact of hypoglycemic events using the EQ-5D-3L (Table 1). ${ }^{23,27}$ Currie et al ${ }^{27}$ examined the HRQoL impact of the worst reported hypoglycemic event. For patients with no events, the mean (SD) value was 0.644 (0.34) compared with 0.758 (0.261), 0.680 (0.341), and $0.522(0.422)$ for those with mild, moderate, and severe events, respectively. Currie et al also examined the impact of fear of hypoglycemia on HRQoL and reported that a 1 unit increase on the hypoglycemia fear survey corresponded to a decrease in EQ-5D-3L score of 0.008 . Solli et $\mathrm{al}^{24}$ also examined the impact of fear of hypoglycemia and reported that the presence of fear of hypoglycemia was associated with 
Table I EQ-5D-3L health state utility/disutility values for diabetes-related complications in patients with type I diabetes

\begin{tabular}{|c|c|c|c|c|}
\hline Study (setting) & Mean (SD) patient characteristics & Health state & Utility/disutility & SD \\
\hline Hart et $\mathrm{al}^{20}$ (the & Age $38(12)$ years & Overall population & 0.88 & 0.17 \\
\hline \multirow[t]{3}{*}{ Netherlands) } & Duration of diabetes $17(\mathrm{II})$ years & Hyperglycemic complaints & -0.071 & - \\
\hline & $\mathrm{HbAIc} 8.3 \%(\mathrm{I} .9 \%)$ & Macrovascular complications & -0.146 & - \\
\hline & & Comorbidity & -0.078 & - \\
\hline Hart et $\mathrm{al}^{21}$ (the & Age $44(12)$ years & Overall population & 0.85 & 0.19 \\
\hline \multirow[t]{3}{*}{ Netherlands) } & Duration of diabetes $23(10)$ years & Hyperglycemia & -0.09 & - \\
\hline & $\mathrm{HbAlc} 7.6 \%(\mathrm{I} .1 \%)$ & Macrovascular complications & -0.135 & - \\
\hline & & Comorbidity & -0.05 & - \\
\hline Hart et $\mathrm{al}^{26}$ (the & Age $38(12)$ years & No complications & 0.982 & - \\
\hline \multirow[t]{7}{*}{ Netherlands) } & Duration of diabetes $17(10)$ years & Intermittent claudication & -0.021 & - \\
\hline & $\mathrm{HbAlc} 8.1 \%(\mathrm{I} .9 \%)$ & Comorbidity & -0.061 & - \\
\hline & & Retinopathy & -0.048 & - \\
\hline & & Hyperglycemia & $-0.07 \mid$ & - \\
\hline & & Change in QoL & & - \\
\hline & & Time $T$ since baseline, years & -0.007 & - \\
\hline & & $\mathrm{T} \times$ intermittent claudication & -0.049 & - \\
\hline \multirow[t]{14}{*}{ Solli et a ${ }^{24}$ (Norway) } & Age 47 (15) years & No complications & 0.90 & $0.88,0.93^{a}$ \\
\hline & Duration of diabetes $22(14)$ years & One complication & 0.76 & $0.66,0.86^{a}$ \\
\hline & $\mathrm{HbAlc} \mathrm{n/a}$ & Two or more complications & 0.55 & $0.37,0.73^{a}$ \\
\hline & & Any complication & 0.68 & $0.59,0.77^{a}$ \\
\hline & & Impaired vision & -0.063 & $-0.169,0.044^{a}$ \\
\hline & & Ischemic heart disease & -0.181 & $\begin{array}{l}-0.331 \\
-0.03 I^{\mathrm{a}}\end{array}$ \\
\hline & & Proteinuria & 0.089 & $-0.036,0.215^{2}$ \\
\hline & & Foot ulcer & -0.083 & $-0.271,0.105^{a}$ \\
\hline & & Stroke & -0.291 & -0.475 \\
\hline & & & & $-0.108^{\mathrm{a}}$ \\
\hline & & Neuropathy & -0.358 & -0.535 \\
\hline & & & & $-0.180^{\mathrm{a}}$ \\
\hline & & BMI increase per unit $\mathrm{kg} / \mathrm{m}^{2}$ & -0.004 & $-0.008,0.00 I^{2}$ \\
\hline & & Fear of hypoglycemia & -0.021 & $-0.073,0.03 I^{a}$ \\
\hline \multirow[t]{8}{*}{ Ozcan et $\mathrm{al}^{28}(\mathrm{UK})^{\mathrm{c}}$} & Age $48(15)$ years & Overall & 0.80 & 0.02 \\
\hline & Duration of diabetes $26(15)$ years & HbA Ic $<7.0 \%$ hypoglycemia & 0.88 & 0.04 \\
\hline & $\mathrm{HbAlc} 7.7 \%(\mathrm{I} .2 \%)$ & aware & & \\
\hline & & $\mathrm{HbAlc}<7.0 \% \mathrm{IHA}$ & 0.83 & 0.05 \\
\hline & & $\begin{array}{l}\text { HbAlc } 7.0 \%-8.5 \% \text { hypoglycemia } \\
\text { aware }\end{array}$ & 0.84 & 0.02 \\
\hline & & $\mathrm{HbAlc} 7.0 \%-8.5 \% \mathrm{IHA}$ & 0.78 & 0.03 \\
\hline & & $\mathrm{HbAlc}>8.5 \%$ hypoglycemia aware & 0.75 & 0.03 \\
\hline & & $\mathrm{HbAlc}>8.5 \% \mathrm{IHA}$ & 0.69 & 0.05 \\
\hline \multirow[t]{3}{*}{ McQueen et al ${ }^{22}$ (US) } & Age $38(12)$ years & Overall (unadjusted) & 0.909 & $0.889,0.930^{\mathrm{a}}$ \\
\hline & Duration of diabetes $22(12)$ years & $1 \%$ increase in $\mathrm{HbAlc}$ & -0.027 & $-0.049,0.006^{2}$ \\
\hline & $\mathrm{HbAlc} 7.55 \%(\mathrm{I} .0 \%)$ & & & \\
\hline \multirow[t]{3}{*}{ Lee et $\mathrm{al}^{25}$ (UK) } & Age 52 years & BMI I $8.5-24.9 \mathrm{~kg} / \mathrm{m}^{2}$ & 0.706 & 0.298 \\
\hline & Duration of diabetes $\mathrm{n} / \mathrm{a}$ & I unit increase in BMI & -0.0076 & $0.003^{\mathrm{b}}$ \\
\hline & $\mathrm{HbAlc} \mathrm{n/a}$ & & & \\
\hline \multirow[t]{3}{*}{ McCoy et $\mathrm{al}^{23}$ (US) } & Age $53(14)$ years & No/mild hypoglycemia & 0.88 & 0.12 \\
\hline & Duration of diabetes $32(17)$ years & Severe hypoglycemia & 0.90 & 0.14 \\
\hline & $\mathrm{HbAlc} 7.6 \%(\mathrm{I} .3 \%)$ & & & \\
\hline \multirow[t]{6}{*}{ Currie et $\mathrm{al}^{27}$ (UK) } & Age 54 (I8) years & Overall & 0.658 & 0.321 \\
\hline & Duration of diabetes $\mathrm{n} / \mathrm{a}$ & Effect of worst hypoglycemic event & & \\
\hline & $\mathrm{HbAlc} 8.4 \%(\mathrm{I} .6 \%)$ & None & 0.644 & 0.34 \\
\hline & & Mild & 0.758 & 0.261 \\
\hline & & Moderate & 0.68 & 0.341 \\
\hline & & Severe & 0.522 & 0.422 \\
\hline
\end{tabular}

Notes: ${ }^{a} 95 \%$ confidence interval. 'Standard error. 'Study used EQ-5D-5L.

Abbreviations: BMI, body mass index; EQ-5D, EuroQol five dimensions questionnaire; HbAlc, glycated hemoglobin; IHA, impaired hypoglycemia awareness; n/a, not available; QoL, quality of life; SD, standard deviation. 
a disutility of -0.021 . In addition, two studies identified in the review used TTO methodology to elicit disutilities associated with mild and severe daytime and nocturnal hypoglycemic events for patients with type 1 diabetes, the results of which are discussed later. ${ }^{36,37}$

\section{QWB questionnaire}

The literature review process identified four studies ${ }^{31-34}$ that reported utilities for complications of type 1 diabetes using the QWB questionnaire (Table 2) ${ }^{41,42}$ The most extensive was a 2002 US-based study by Coffey et al, ${ }^{33}$ which reported utility values associated with obesity, retinopathy, nephropathy, dialysis, neuropathy, amputation, stroke, and congestive heart failure. For a male with no complications, Coffey et al reported a utility of 0.672 , which is notably lower than the corresponding value reported in the EQ-5D-3L studies by Solli et $\mathrm{al}^{24}$ and Hart et al. ${ }^{26}$ Coffey et $\mathrm{al}^{33}$ reported that the health states associated with the largest utility decrements were blindness in both eyes $(-0.208$ [0.013]), amputation $(-0.116[0.023])$, and stroke $(-0.105[0.030])$.

Table 2 QWB health state utility/disutility values for diabetes-related complications in patients with type I diabetes

\begin{tabular}{|c|c|c|c|c|}
\hline Study (setting) & $\begin{array}{l}\text { Mean (SD) patient } \\
\text { characteristics }\end{array}$ & Health state & Utility/disutility & SD \\
\hline \multirow[t]{20}{*}{ Coffey et $\mathrm{al}^{33}$ (US) } & Age 35 years $^{\mathrm{a}}$ & Male no complications & 0.672 & $0.007^{\mathrm{b}}$ \\
\hline & Duration of diabetes & Female sex & -0.033 & $0.008^{b}$ \\
\hline & 20 years $^{\mathrm{a}}$ & Obesity & -0.016 & $0.010^{\mathrm{b}}$ \\
\hline & $\mathrm{HbAlc} \mathrm{n/a}$ & Retinopathy & & \\
\hline & & Blind in one eye & -0.024 & $0.015^{b}$ \\
\hline & & Blind in both eyes & -0.208 & $0.013^{b}$ \\
\hline & & Nephropathy & & \\
\hline & & Diabetic kidney disease & -0.017 & $0.010^{\mathrm{b}}$ \\
\hline & & Dialysis & -0.023 & $0.027^{b}$ \\
\hline & & Neuropathy & & \\
\hline & & Tingling and burning & -0.067 & $0.014^{b}$ \\
\hline & & Neuropathy & -0.055 & $0.010^{\mathrm{b}}$ \\
\hline & & Sores & -0.076 & $0.016^{\mathrm{b}}$ \\
\hline & & Amputation & -0.116 & $0.023^{b}$ \\
\hline & & Stroke & & \\
\hline & & TIA or stroke & -0.018 & $0.022^{b}$ \\
\hline & & Stroke with residual & -0.105 & $0.030^{\mathrm{b}}$ \\
\hline & & Cardiovascular disease & & \\
\hline & & Congestive heart failure & -0.058 & $0.022^{b}$ \\
\hline & & $\begin{array}{l}\text { High blood pressure/high blood } \\
\text { pressure with medication }\end{array}$ & -0.032 & $0.010^{\mathrm{b}}$ \\
\hline \multirow[t]{10}{*}{ Tabaei et $\mathrm{a}^{32}$ (US) } & Age 33 years $^{\mathrm{a}}$ & Overall population (no symptoms of & 0.63 & \\
\hline & Duration of diabetes & hyperglycemia in previous month) & & \\
\hline & 19 years $^{\mathrm{a}}$ & Frequency of hyperglycemic & -0.020 & $0.005^{b}$ \\
\hline & $\mathrm{HbAlc} 8.3 \%$ & $\begin{array}{l}\text { symptoms in previous month } \\
(0,1-4,5-8,9-12,12+)\end{array}$ & & \\
\hline & & Female sex & -0.040 & $0.012^{\mathrm{b}}$ \\
\hline & & Neuropathy & -0.068 & $0.014^{b}$ \\
\hline & & Blindness & -0.132 & $0.016^{\mathrm{b}}$ \\
\hline & & Hypertension & -0.056 & $0.014^{b}$ \\
\hline & & Stroke & -0.121 & $0.045^{b}$ \\
\hline & & Peripheral vascular disease & -0.080 & $0.020^{\mathrm{b}}$ \\
\hline Sureshkumar & Age $n / a$ & ESRD (on transplant waiting list) & 0.55 & 0.04 \\
\hline \multirow[t]{3}{*}{ et $\mathrm{al}^{31}$ (US) } & Duration of diabetes $n / a$ & Simultaneous pancreas-kidney transplant & 0.62 & 0.11 \\
\hline & $\mathrm{HbAlc} \mathrm{n/a}$ & Living kidney transplant & 0.54 & 0.06 \\
\hline & & Cadaver kidney transplant & 0.61 & 0.11 \\
\hline \multirow{4}{*}{$\begin{array}{l}\text { Sureshkumar } \\
\text { et } \mathrm{al}^{34} \text { (US) }\end{array}$} & Age $n / a$ & Simultaneous kidney-pancreas & 0.67 & 0.12 \\
\hline & Duration of & transplant & & \\
\hline & diabetes $n / a$ & Kidney-alone transplant & 0.63 & 0.10 \\
\hline & $\mathrm{HbAlc} \mathrm{n/a}$ & & & \\
\hline
\end{tabular}

Notes: aMedian. 'btandard error.

Abbreviations: ESRD, end-stage renal disease; HbAlc, glycated hemoglobin; n/a, not available; QWB, Quality of Well-Being; SD, standard deviation; TIA, transient ischemic attack. 
Another US-based study by Tabaei et al also used the QWB questionnaire and reported similar values to Coffey et al for stroke and neuropathy although Tabaei et al reported less HRQoL impairment associated with blindness (disutility of -0.132 [0.016]) than Coffey et $\mathrm{al}^{33}$ and studies that used direct methods to elicit utility values (Lee et $\mathrm{al}^{35}$ and Kiberd and $\operatorname{Larson}^{39}$ ).

Two other studies, both by Sureshkumar et al, ${ }^{31,34}$ used the QWB instrument to determine utility values for type 1 diabetes patients undergoing kidney transplantation or simultaneous kidney-pancreas transplantation (Table 2). In both studies, simultaneous kidney-pancreas transplantation was found to lead to greater improvements in HRQoL relative to kidney transplantation alone.

\section{I5D questionnaire}

Two studies, both conducted in Finland, determined utility values using the $15 \mathrm{D}$ instrument. ${ }^{43}$ The first study by Hannula et $\mathrm{al}^{29}$ focused solely on the impact of diabetic retinopathy, while the second study by Ahola et al ${ }^{30}$ examined the impact of several different complications using a Tobit regression model (Table 3 ). Ahola et $\mathrm{al}^{30}$ reported a utility value for a patient with normoalbuminuria of 0.928 , and the renal complications of dialysis and transplant being associated with utility decrements of -0.082 and -0.053 , respectively, while proliferative retinopathy was associated with a disutility of -0.007 . Estimates of utility values from the $15 \mathrm{D}$ instrument for patients with no complications were notably higher than those reported using other methodologies.

\section{Direct methods:TTO and SG}

A total of five studies identified during the literature review process used direct methods to elicit utility values, two of which focused exclusively on hypoglycemic events
(Table 4). ${ }^{36,37}$ One US-based study used TTO methodology to determine utility values for several states including blindness, ESRD, angina, stroke, and amputation. ${ }^{35}$ The state associated with the most severe HRQoL impact was stroke, which has a mean (SD) utility value of 0.34 (0.31). ESRD and blindness were also associated with substantial impairment in HRQoL and had mean (SD) utility values of 0.47 (0.32) and 0.52 (0.33), respectively. Similar values were reported by Kiberd and Larson ${ }^{39}$ using SG methodology.

Two studies used SG methods to determine utility values associated with renal disease and transplant states. As expected, both kidney and simultaneous kidney-pancreas transplants were associated with substantially higher utility values than dialysis. Utility values of 0.57 and 0.70 were reported for dialysis compared with 0.80 and 0.72 for kidney transplant and 0.85 and 0.95 for simultaneous kidney-pancreas transplant. ${ }^{38,39}$ The additional HRQoL benefit with simultaneous kidney-pancreas transplant may be due to the potential for achieving a euglycemic and insulin-independent state. $^{44}$

\section{Discussion}

Overall, the findings of the literature review showed that for patients with type 1 diabetes, both acute and chronic complications were associated with substantial impairments in HRQoL. Chronic complications including ESRD, stroke, and blindness were generally associated with the largest decrements in HRQoL. Several other factors, including poor glycemic control, obesity, and fear of hypoglycemia, were also associated with detrimental effects on HRQoL. However, patients with type 1 diabetes and no complications were found to have utility values typically $\geq 0.90$, indicating good HRQoL (comparable with the general population). The magnitude of impairment associated with complications was

Table 3 I5D health state utility/disutility values for diabetes-related complications in patients with type I diabetes

\begin{tabular}{|c|c|c|c|c|}
\hline Study (setting) & Mean (SD) patient characteristics & Health state & Utility/disutility & SD \\
\hline Hannula et $\mathrm{al}^{29}$ & Age $29(3)$ years & No or non-PDR & 0.965 & 0.044 \\
\hline \multirow[t]{2}{*}{ (Finland) } & Duration of diabetes $23(4)$ years & PDR & 0.931 & 0.086 \\
\hline & $\mathrm{HbAlc} \mathrm{n/a}$ & & & \\
\hline Ahola et $\mathrm{a}^{30}$ & Age $46(12)$ years & Normoalbuminuria & 0.928 & - \\
\hline \multirow[t]{9}{*}{ (Finland) } & Duration of diabetes $29(13)$ years & Microalbuminuria & -0.003 & - \\
\hline & $\mathrm{HbAIc} 8.0 \%(\mathrm{I} .6 \%)$ & Macroalbuminuria & -0.036 & - \\
\hline & & Dialysis & -0.082 & - \\
\hline & & Renal transplantation & -0.053 & - \\
\hline & & Proliferative retinopathy & -0.007 & - \\
\hline & & Age & -0.002 & - \\
\hline & & Duration & -0.001 & - \\
\hline & & BMI & -0.001 & - \\
\hline & & $\mathrm{HbAlc}$ & -0.006 & - \\
\hline
\end{tabular}

Abbreviations: BMI, body mass index; HbAIc, glycated hemoglobin; n/a, not available; PDR, proliferative diabetic retinopathy; SD, standard deviation; I5D, I5 dimensional. 
Table 4 Health state utility/disutility values for diabetes-related complications in patients with type I diabetes using direct methods (TTO and SG)

\begin{tabular}{|c|c|c|c|c|}
\hline Study (setting) & $\begin{array}{l}\text { Mean (SD) patient } \\
\text { characteristics }\end{array}$ & Health state & Utility/disutility & SD \\
\hline \multicolumn{5}{|l|}{ TTO } \\
\hline \multirow[t]{6}{*}{ Lee et $\mathrm{al}^{35}$ (US) } & Age 39 (I4) years & Overall population & 0.81 & 0.25 \\
\hline & Duration of diabetes 22 & Blindness & 0.52 & 0.33 \\
\hline & (I3) years & ESRD & 0.47 & 0.32 \\
\hline & $\mathrm{HbAlc} \mathrm{n/a}$ & Angina & 0.74 & 0.28 \\
\hline & & Stroke & 0.34 & 0.31 \\
\hline & & Amputation & 0.73 & 0.30 \\
\hline \multirow[t]{6}{*}{ Harris et $\mathrm{al}^{36}$ (Canada) } & Age 39 years & Diabetes with no hypoglycemic & 0.8314 & $0.792,0.868^{\mathrm{a}}$ \\
\hline & Duration of diabetes $\mathrm{n} / \mathrm{a}$ & events & & \\
\hline & $\mathrm{HbAlc} \mathrm{n/a}$ & Nonsevere daytime event & -0.0030 & $-0.001,-0.005^{a}$ \\
\hline & & Nonsevere nocturnal event & -0.0052 & $-0.003,-0.008^{a}$ \\
\hline & & Severe daytime event & -0.0277 & $-0.009,-0.050^{\mathrm{a}}$ \\
\hline & & Severe nocturnal event & -0.0657 & $-0.021,-0.122^{\mathrm{a}}$ \\
\hline \multirow[t]{4}{*}{ Evans et $\mathrm{al}^{37}$ (Multinational) } & Age $39(14)$ years & Nonsevere daytime event & -0.004 & $-0.001,-0.006^{\mathrm{a}}$ \\
\hline & Duration of diabetes $n / a$ & Nonsevere nocturnal event & -0.008 & $-0.005,-0.01 \mathrm{I}^{\mathrm{a}}$ \\
\hline & $\mathrm{HbAlc} \mathrm{n/a}$ & Severe daytime event & -0.047 & $-0.033,-0.062^{\mathrm{a}}$ \\
\hline & & Severe nocturnal event & -0.051 & $-0.037,-0.065^{\mathrm{a}}$ \\
\hline \multicolumn{5}{|c|}{ ( } \\
\hline \multirow[t]{8}{*}{ Kiberd et $\mathrm{al}^{39}$ (US) } & Age $n / a$ & Early overt nephropathy ${ }^{b}$ & 0.75 & 0.05 \\
\hline & Duration of diabetes $\mathrm{n} / \mathrm{a}$ & Functioning pancreas transplant & 0.95 & 0.02 \\
\hline & $\mathrm{HbAlc} \mathrm{n/a}$ & $\begin{array}{l}\text { Functioning kidney-pancreas } \\
\text { transplant }\end{array}$ & 0.95 & 0.02 \\
\hline & & Functioning kidney transplant & 0.72 & 0.05 \\
\hline & & Dialysis & 0.57 & 0.05 \\
\hline & & Blindness & 0.48 & 0.06 \\
\hline & & Blindness and kidney transplant & 0.49 & 0.07 \\
\hline & & Blindness and dialysis & 0.40 & 0.06 \\
\hline \multirow[t]{4}{*}{ Knoll et $\mathrm{al}^{38}$ (US) } & Age 31 (10) years & Dialysis & 0.70 & 0.26 \\
\hline & Duration of diabetes 14 & Kidney transplantation & 0.80 & 0.17 \\
\hline & (I0) years & Kidney-pancreas transplantation & 0.85 & 0.12 \\
\hline & $\mathrm{HbAlc} \mathrm{n/a}$ & & & \\
\hline
\end{tabular}

Notes: ${ }^{9} 95 \%$ confidence interval. ${ }^{b}$ Defined as macroproteinuria (>300 mg/d) and preserved renal function (GFR $\left.80-100 \mathrm{~mL} / \mathrm{min}\right)$ despite ACE inhibition therapy.

Abbreviations: ACE, angiotensin-converting enzyme; ESRD, end-stage renal disease; GFR, glomerular filtration rate; HbAlc, glycated hemoglobin; n/a, not available; SD, standard deviation; SG, standard gamble; TTO, time trade-off.

found to vary substantially between studies. Several factors may have influenced this, including the method used to determine utilities and differences in the characteristics of the study populations, such as age and duration of disease. Differences in utility values determined using different methods were evident when comparing utility values obtained from the $15 \mathrm{D}$ with those using other methods, including EQ-5D and TTO, and particularly, the QWB questionnaire. The phenomenon of higher utility values associated with the 15D questionnaire has also been reported in other therapy areas including $\mathrm{HIV}^{45}$ and rheumatoid arthritis. ${ }^{46}$ For example, in a study of patients with HIV conducted in Norway, Stavem et a ${ }^{45}$ reported a mean (SD) overall utility score of 0.86 using the 15D compared with 0.77 using the EQ-5D-3L. Despite the fact that the $15 \mathrm{D}$ consistently tends to generate higher utility values than other instruments, the underlying reason for the discrepancy remains unclear.
A previous systematic review of utilities by Arnold et al ${ }^{47}$ across multiple therapy areas noted that direct methods were consistently associated with higher utilities compared with indirect methods, although again the causal mechanism for this was unclear. Additionally, in this instance, direct comparison of utilities from different studies is complicated by heterogeneity in the definition of health states across studies and also the use of broad categories in some studies that include patients with complications that may be asymptomatic or associated with minimal symptoms as well as patients with severely compromised HRQoL. Microeconomic research in the utility theory and decision making under uncertainty has led to identification of up to four potential sources of bias with respect to SG and TTO methods. These may help explain in part why SG-based utilities differ from TTO. ${ }^{48}$

Differences in utilities were also evident even between studies that used that same instrument. This may be partly due 
to differences in patient- and disease-related factors such as age and duration of disease. For EQ-5D-3L studies, the use of different scoring algorithms may also have contributed to between-study differences in utilities. Of the eight EQ-5D-3L and one EQ-5D-5L studies identified in the current review, six did not state which scoring algorithm was used, one used US TTO tariff values, and two used UK values. The choice of scoring algorithm used can have a notable impact on utility values for diabetic complications in type 2 diabetes, ${ }^{49}$ and as country-specific algorithms are not available for all countries, investigators must select the most appropriate alternative to use.

A total of 20 utility studies conducted exclusively in patients with type 1 diabetes were identified via a combination of literature review of key databases and supplementary hand searches. Almost half $(n=9)$ of these used the NICEpreferred EQ-5D to elicit utilities, with approximately one-quarter using other generic preference-based methods and the remainder using direct methods such as TTO and $\mathrm{SG}$. However, despite the preference of investigators for the EQ-5D-3L, there remains a paucity of EQ-5D-3L utility data from type 1 diabetes populations for several key complications including ESRD (dialysis and renal transplantation) and lower limb amputation. Additionally, several EQ-5D-3L studies used broad umbrella terms such as macrovascular complications, which will apply the same decrement for a patient experiencing angina as for a patient experiencing a cerebrovascular accident or myocardial infarction. Similarly, the term retinopathy is likely to capture patients with background diabetic retinopathy and minimal symptoms as well as those with advanced proliferative diabetic retinopathy and visual impairment.

Utility data form an integral part of cost-effectiveness analysis and, for a health economic analysis in type 1 diabetes, an investigator would ideally be able to populate a cost-effectiveness model with utility values exclusively from type 1 diabetes populations using consistent methodology. However, economic models with health states including ESRD and amputation cannot currently be populated exclusively with EQ-5D-3L values derived from patients with type 1 diabetes. Equally, there is a paucity of QWB data on health states relating to ischemic heart disease, again meaning that an economic model with extensive health states could not be populated exclusively with QWB-derived utilities from type 1 diabetes patients. Consequently, for cost-effectiveness analyses in type 1 diabetes, investigators are presented with the choice of using data from type 2 diabetes populations as a proxy or selecting a set of type 1 diabetes utility values derived using different methods. As shown in this review, the use of different methods can result in substantial differences in utility values for the same health state; consequently, the use of utilities derived using a variety of different methods could potentially obfuscate the findings of cost-effectiveness analyses. ${ }^{50}$ Several studies in this review present data on complications for both type 1 and type 2 diabetes patients. ${ }^{24,32,33,36,37}$ In one study by Solli et al, the utility decrements associated with ischemic heart disease, stroke, and neuropathy were substantially greater for patients with type 1 diabetes than for those with type 2 diabetes, suggesting the use of data from type 2 diabetes patients as a proxy for type 1 diabetes may be inappropriate. The authors postulate that this may have been attributable to the younger age of the type 1 group, suggesting that complications would likely have a greater negative impact on younger patients with lower levels of comorbidity and who may struggle to accept poor health states. However, the magnitude of differences between type 1 and type 2 diabetes patients was considerably smaller in two other studies that used the QWB questionnaire, despite the younger age of the type 1 diabetes groups compared with type 2 diabetes patients. ${ }^{32,33}$ This suggests that data from type 2 diabetes patients may represent a valid proxy in certain cases. Interestingly, three studies that focused on hypoglycemic events reported that the utility decrement associated with severe hypoglycemic events (both daytime and nocturnal events) was greater for patients with type 2 diabetes relative to those with type 1 diabetes. ${ }^{27,36,37}$

In addition to diabetes-related complications, several other factors including glycemic control, fear or hypoglycemia, impaired awareness of hypoglycemia, and BMI were shown to influence HRQoL in type 1 diabetes. In particular, two recent studies demonstrated that poor glycemic control was associated with lower HRQoL, with one study showing that poor glycemic control remained a significant predictor of utility score following adjustment for diabetes-related complications, medications, and demographics. ${ }^{22}$ Moreover, the authors suggest that, as an independent predictor of HRQoL, HbA1c is a factor that should be considered for incorporation into future cost-effectiveness analyses in type 1 diabetes. In the second study by Ozcan et al, ${ }^{28}$ impaired awareness of hypoglycemia was also found to contribute to lower utility values across all levels of glycemic control. Impaired awareness of hypoglycemia has been reported in up to $20 \%$ of type 1 diabetes patients and can be particularly problematic in patients with long-standing disease. ${ }^{51,52}$ It can lead to anxiety and fear that can impair HRQoL. While Ozcan et al investigated the combined effect of impaired awareness 
of hypoglycemia and poor glycemic control, two other studies addressed exclusively the impact of fear of hypoglycemia on HRQoL, with Currie et al translating changes in the fear of hypoglycemia scale into decrements of EQ-5D-3L score. Other modifiable risk factors including BMI and hypertension were also shown to influence HRQoL, although these factors were only investigated in a small number of studies.

Although this review was explicitly designed to examine the impact of diabetes-related complications, fear of hypoglycemia, BMI, and glycemic control, on HRQoL, several studies identified during the literature review process (including some excluded during the full-text screening stage) quantified the effect of age and disease duration on HRQoL in type 1 diabetes..$^{19,26,30,53}$ Both advancing age and longer duration of disease were consistently associated with declining HRQoL, both in the presence and absence of complications and should be taken into account in cost-effectiveness analyses. For example, using the $15 \mathrm{D}$, Ahola et al reported a utility of $0.933(0.094)$ for a male aged $25-34$ years with no complications, declining to $0.826(0.106)$ for a male aged $>65$ years with no complications. The corresponding values for a male with complications were 0.911 (0.105) and 0.825 (0.090), respectively. ${ }^{30}$ Similarly, using the EQ-5D-3L, Hart et al ${ }^{26}$ reported an annual decline in utility of 0.007 .

A limitation of this review was that no formal assessment of study quality was performed, and some studies may have limitations associated with their design, although the observational and noninterventional nature of most included studies means that they are unlikely to have been subject to limitations such as bias or selective reporting of data. For example, those using retrospective data collection may have been exposed to the risk of response shift. A response shift occurs when there is "a change in the meaning of one's self-evaluation of a target construct" due to recalibration, reprioritization, or reconceptualization. ${ }^{54}$ This phenomenon has been reported in several therapy areas including in type 1 diabetes patients in receipt of simultaneous kidney-pancreas transplants. Following successful transplantation, patients retrospectively valued their pre-transplant HRQoL lower than their actual pre-transplant valuation of HRQoL. ${ }^{55}$ Response shift is also possible owing to adaptation to chronic disease $^{56}$ and could potentially have implications if used in cost-effectiveness in terms of over- or underestimating utility values for particular health states. A second limitation is that studies conducted exclusively in pediatric populations were excluded. Type 1 diabetes is a chronic disease typically diagnosed in childhood or adolescence; therefore, pediatric patients represent a substantial proportion of the overall type 1 diabetes population. Utility values obtained from adult populations may not be generalizable in pediatric populations as several studies have shown that utility values decline with age. For example, in one study included here, Lee et $\mathrm{al}^{35}$ examined utility values for both adults and pediatric patients (using parent proxy report) and report notably higher values for children (aged 8-18 years) than for adults.

Overall, evidence from published studies in type 1 diabetes patients shows that diabetes-related complications and poor glycemic control have a negative impact on HRQoL, with stroke, ESRD, and blindness having the most detrimental effects. This review identified 20 articles that reported utility values in populations with type 1 diabetes published in the last 15 years. Direct and indirect methods were used, and the paucity of data for some complications in this population means that the HRQoL impact of all diabetes-related complications has not been assessed by a single instrument or methodology. Although utility values using a range of different methodologies are available for most major diabetesrelated complications, there are data gaps in type 1 diabetes populations for a small number of complications such as amputation and foot ulcer. These areas may represent a viable avenue for future research to fill the few remaining gaps in the type 1 diabetes-specific literature.

\section{Acknowledgment}

This study was supported by funding from Eli Lilly and Company.

\section{Disclosure}

Three of the authors (KSB, JPB, and KN) are current employees of Eli Lilly. Three of the authors (JSP, WJV, and BH) are current employees of Ossian Health Economics and Communications, which has received consulting fees from Eli Lilly. The authors report no other conflicts of interest in this work.

\section{References}

1. United States Office of Disease Prevention and Health Promotion [webpage on the Internet]. Health-related quality of life and well being. Available from: http://www.healthypeople.gov/2020/about/foundationhealth-measures/Health-Related-Quality-of-Life-and-Well-Being. Accessed December 16, 2014.

2. International Society for Pharmacoeconomics and Outcomes Research [webpage on the Internet]. Comparison of pharmacoeconomic guidelines. Available from: http://www.ispor.org/PEguidelines/COMP1.asp. Accessed March 5, 2015.

3. Papaioannou D, Brazier J, Paisley S; for the NICE Decision Support Unit [webpage on the Internet]. NICE DSU technical support document 9: the identification, review and synthesis of health state utility values from the literature. Available from: http://www.nicedsu.org. uk/TSD9\%20HSUV\%20values_FINAL.pdf. Accessed December 18, 2014. 
4. Woo G, Tomlinson G, Yim C, et al. Health state utilities and quality of life in patients with hepatitis B. Can J Gastroenterol. 2012;26(7):445-451.

5. Price D, Gray A, Gale R, et al. Cost-utility analysis of indacaterol in Germany: a once-daily maintenance bronchodilator for patients with COPD. Respir Med. 2011;105(11):1635-1647.

6. Rashidi AA, Anis AH, Marra CA. Do visual analogue scale (VAS) derived standard gamble (SG) utilities agree with Health Utilities Index utilities? A comparison of patient and community preferences for health status in rheumatoid arthritis patients. Health Qual Life Outcomes. 2006;4:25

7. Sullivan PW, Ghushchyan V. Mapping the EQ-5D index from the SF-12: US general population preferences in a nationally representative sample. Med Decis Making. 2006;26(4):401-409.

8. Petrou S, Hockley C. An investigation into the empirical validity of the EQ-5D and SF-6D based on hypothetical preferences in a general population. Health Econ. 2005;14(11):1169-1189.

9. American Diabetes Association. Diagnosis and classification of diabetes mellitus. Diabetes Care. 2004;27(suppl 1):S5-S10.

10. Shearer A, Bagust A, Sanderson D, Heller S, Roberts S. Cost-effectiveness of flexible intensive insulin management to enable dietary freedom in people with type 1 diabetes in the UK. Diabet Med. 2004;21(5):460-467.

11. St Charles ME, Sadri H, Minshall ME, Tunis SL. Health economic comparison between continuous subcutaneous insulin infusion and multiple daily injections of insulin for the treatment of adult type 1 diabetes in Canada. Clin Ther. 2009;31(3):657-667.

12. Palmer AJ, Roze S, Valentine WJ, Smith I, Wittrup-Jensen KU. Costeffectiveness of detemir-based basal/bolus therapy versus NPH-based basal/bolus therapy for type 1 diabetes in a UK setting: an economic analysis based on meta-analysis results of four clinical trials. Curr Med Res Opin. 2004;20(11):1729-1746.

13. Goodall G, Sarpong EM, Hayes C, Valentine WJ. The consequences of delaying insulin initiation in UK type 2 diabetes patients failing oral hyperglycaemic agents: a modelling study. BMC Endocr Disord. 2009;9:19.

14. Kostev K, Rathmann W. Changes in time to insulin initiation in type 2 diabetes patients: a retrospective database analysis in Germany and UK (2005-2010). Prim Care Diabetes. 2013;7(3):229-233.

15. Constantino MI, Molyneaux L, Limacher-Gisler F, et al. Long-term complications and mortality in young-onset diabetes: type 2 diabetes is more hazardous and lethal than type 1 diabetes. Diabetes Care. 2013;36(12):3863-3869.

16. Dart AB, Martens PJ, Rigatto C, Brownell MD, Dean HJ, Sellers EA. Earlier onset of complications in youth with type 2 diabetes. Diabetes Care. 2014;37(2):436-443.

17. van Rhijn BD, Smout AJ, Bredenoord AJ. Disease duration determines health-related quality of life in adult eosinophilic esophagitis patients. Neurogastroenterol Motil. 2014;26(6):772-778.

18. Carr CW, Veledar E, Chen SC. Factors mediating the impact of chronic pruritus on quality of life. JAMA Dermatol. 2014;150(6):613-620.

19. Sparring V, Nyström L, Wahlström R, Jonsson PM, Ostman J, Burström $\mathrm{K}$. Diabetes duration and health-related quality of life in individuals with onset of diabetes in the age group 15-34 years - a Swedish populationbased study using EQ-5D. BMC Public Health. 2013;13:377.

20. Hart HE, Bilo HJ, Redekop WK, Stolk RP, Assink JH, Meyboom-de Jong B. Quality of life of patients with type I diabetes mellitus. Qual Life Res. 2003;12(8):1089-1097.

21. Hart HE, Redekop WK, Bilo HJ, Meyboom-de Jong B, Berg M. Health related quality of life in patients with type I diabetes mellitus: generic \& disease-specific measurement. Indian J Med Res. 2007;125:203-216.

22. McQueen RB, Ellis SL, Maahs DM, et al. Association between glycated hemoglobin and health utility for type 1 diabetes. Patient. 2014;7(2):197-205.

23. McCoy RG, Van Houten HK, Ziegenfuss JY, Shah ND, Wermers RA, Smith SA. Self-report of hypoglycemia and health-related quality of life in patients with type 1 and type 2 diabetes. Endocr Pract. 2013;19(5):792-799.
24. Solli O, Stavem K, Kristiansen IS. Health-related quality of life in diabetes: the associations of complications with EQ-5D scores. Health Qual Life Outcomes. 2010;8:18.

25. Lee AJ, Morgan CL, Morrissey M, Wittrup-Jensen KU, Kennedy-Martin T, Currie CJ. Evaluation of the association between the EQ-5D (healthrelated utility) and body mass index (obesity) in hospital-treated people with type 1 diabetes, type 2 diabetes and with no diagnosed diabetes. Diabet Med. 2005;22(11):1482-1486.

26. Hart HE, Redekop WK, Berg M, Bilo HJ, Meyboom-de Jong B. Factors that predicted change in health-related quality of life were identified in a cohort of diabetes mellitus type 1 patients. $J$ Clin Epidemiol. 2005;58(11):1158-1164.

27. Currie CJ, Morgan CL, Poole CD, Sharplin P, Lammert M, McEwan P. Multivariate models of health-related utility and the fear of hypoglycaemia in people with diabetes. Curr Med Res Opin. 2006;22(8):1523-1534.

28. Ozcan S, Amiel SA, Rogers H, et al. Poorer glycaemic control in type 1 diabetes is associated with reduced self-management and poorer perceived health: a cross-sectional study. Diabetes Res Clin Pract. 2014;106(1):35-41.

29. Hannula V, Hautala N, Sintonen H, Falck A. Health-related quality of life - using the 15D instrument - of young adults with type 1 diabetes since childhood. Population-based Oulu cohort study of diabetic retinopathy. Acta Ophthalmol. 2014;92:205-208.

30. Ahola AJ, Saraheimo M, Forsblom C, et al; FinnDiane Study Group. Health-related quality of life in patients with type 1 diabetes - association with diabetic complications (the FinnDiane Study). Nephrol Dial Transplant. 2010;25:1903-1908.

31. Sureshkumar KK, Patel BM, Markatos A, Nghiem DD, Marcus RJ. Quality of life after organ transplantation in type 1 diabetics with endstage renal disease. Clin Transplant. 2006;20(1):19-25.

32. Tabaei BP, Shill-Novak J, Brandle M, Burke R, Kaplan RM, Herman WH. Glycemia and the quality of well-being in patients with diabetes. Qual Life Res. 2004;13(6):1153-1161.

33. Coffey JT, Brandle M, Zhou H, et al. Valuing health-related quality of life in diabetes. Diabetes Care. 2002;25(12):2238-2243.

34. Sureshkumar KK, Mubin T, Mikhael N, Kashif MA, Nghiem DD, Marcus RJ. Assessment of quality of life after simultaneous pancreaskidney transplantation. Am J Kidney Dis. 2002;39(6):1300-1306.

35. Lee JM, Rhee K, O'Grady MJ, et al; JDRF Continuous Glucose Monitoring Study Group. Health utilities for children and adults with type 1 diabetes. Med Care. 2011;49(10):924-931.

36. Harris S, Mamdani M, Galbo-Jørgensen CB, Bøgelund M, Gundgaard J, Groleau D. The effect of hypoglycemia on health-related quality of life: Canadian results from a multinational time trade-off survey. Can J Diabetes. 2014;38(1):45-52.

37. Evans M, Khunti K, Mamdani M, et al. Health-related quality of life associated with daytime and nocturnal hypoglycaemic events: a time trade-off survey in five countries. Health Qual Life Outcomes. 2013;11:90.

38. Knoll GA, Nichol G. Dialysis, kidney transplantation, or pancreas transplantation for patients with diabetes mellitus and renal failure: a decision analysis of treatment options. J Am Soc Nephrol. 2003;14(2):500-515.

39. Kiberd BA, Larson T. Estimating the benefits of solitary pancreas transplantation in nonuremic patients with type 1 diabetes mellitus: a theoretical analysis. Transplantation. 2000;70(7):1121-1127.

40. EuroQol Group. EuroQol - a new facility for the measurement of health related quality of life. Health Policy. 1990;16:199-208.

41. Kaplan RM, Ganiats TG, Sieber WJ, Anderson JP. The quality of wellbeing scale: critical similarities and differences with SF-36. Int J Qual Health Care. 1998;10(6):509-520.

42. Kaplan RM, Sieber WJ, Ganiats TG. The Quality of Well-Being Scale. Comparison of the interviewer-administered version with a selfadministered questionnaire. Psychol Health. 1997;12:783-791.

43. Sintonen $H$. The $15 \mathrm{D}$ instrument of health-related quality of life: properties and applications. Ann Med. 2001;33(5):328-336.

44. Hakim NS. Pancreatic transplantation for patients with type I diabetes. HPB (Oxford). 2002;4:59-61. 
45. Stavem K, Frøland SS, Hellum KB. Comparison of preference-based utilities of the 15D, EQ-5D and SF-6D in patients with HIV/AIDS. Qual Life Res. 2005;14(4):971-980.

46. Lillegraven S, Kristiansen IS, Kvien TK. Comparison of utility measures and their relationship with other health status measures in 1041 patients with rheumatoid arthritis. Ann Rheum Dis. 2010;69(10):1762-1767.

47. Arnold D, Girling A, Stevens A, Lilford R. Comparison of direct and indirect methods of estimating health state utilities for resource allocation: review and empirical analysis. BMJ. 2009;339:b2688.

48. Bleichrodt H. A new explanation for the difference between time trade-off utilities and standard gamble utilities. Health Econ. 2002;11(5):447-456.

49. Kiadaliri AA, Gerdtham UG, Eliasson B, Gudbjörnsdottir S, Svensson AM, Carlsson KS. Health utilities of type 2 diabetes-related complications: a cross-sectional study in Sweden. Int J Environ Res Public Health. 2014;11(5):4939-4952.

50. Boye KS, Matza LS, Feeny DH, Johnston JA, Bowman L, Jordan JB Challenges to time trade-off utility assessment methods: when should you consider alternative approaches? Expert Rev Pharmacoecon Outcomes Res. 2014;14(3):437-450.
51. Geddes J, Schopman JE, Zammitt NN, Frier BM. Prevalence of impaired awareness of hypoglycaemia in adults with type 1 diabetes. Diabet Med. 2008;25(4):501-504.

52. Olsen SE, Asvold BO, Frier BM, Aune SE, Hansen LI, Bjørgaas MR. Hypoglycaemia symptoms and impaired awareness of hypoglycaemia in adults with type 1 diabetes: the association with diabetes duration. Diabet Med. 2014;31(10):1210-1217.

53. Hahl J, Hämäläinen H, Sintonen H, Simell T, Arinen S, Simell O. Health-related quality of life in type 1 diabetes without or with symptoms of long-term complications. Qual Life Res. 2002;11(5): $427-436$.

54. Sprangers MA, Schwartz CE. Integrating response shift into health related quality of life research: a theoretical model. Soc Sci Med. 1999;48:1507-1515.

55. Adang EM, Kootstra G, Engel GL, van Hooff JP, Merckelbach HL. Do retrospective and prospective quality of life assessments differ for pancreas-kidney transplant recipients? Transpl Int. 1998;11(1): 11-15.

56. Postulart D, Adang EM. Response shift and adaptation in chronically ill patients. Med Decis Making. 2000;20(2):186-193.

\section{ClinicoEconomics and Outcomes Research}

\section{Publish your work in this journal}

ClinicoEconomics and Outcomes Research is an international, peerreviewed open-access journal focusing on health technology assessment, pharmacoeconomics and outcomes research in the areas of diagnosis, medical devices, and clinical, surgical and pharmacological intervention. The economic impact of health policy and health systems
Submit your manuscript here: https://www.dovepress.com/clinicoeconomics-and-outcomes-research-jour

organization also constitute important areas of coverage. The manuscript management system is completely online and includes a very quick and fair peer-review system, which is all easy to use. Visit http://www.dovepress.com/testimonials.php to read real quotes from published authors. 